\title{
Microencapsulated bitter compounds (from Gentiana lutea) reduce daily energy intakes in humans
}

\author{
Ilario Mennella ${ }^{1,2}$, Vincenzo Fogliano ${ }^{2}$, Rosalia Ferracane ${ }^{1}$, Marco Arlorio ${ }^{3}$, Franco Pattarino ${ }^{3}$ and \\ Paola Vitaglione ${ }^{1 *}$ \\ ${ }^{1}$ Department of Agricultural Sciences, University of Naples 'Federico II', Via Università 100, 80055 Portici (NA), Italy \\ ${ }^{2}$ Food Quality and Design Group, Wageningen University and Research Centre, PO Box 8129, 6700 EV Wageningen, \\ The Netherlands \\ ${ }^{3}$ Dipartimento di Scienze del Farmaco, Università degli Studi del Piemonte Orientale 'A. Avogadro', Largo Donegani 2, 28100 \\ Novara, Italy \\ (Submitted 28 March 2016 - Final revision received 1 October 2016 - Accepted 10 October 2016 - First published online 10 November 2016)
}

\begin{abstract}
Mounting evidence showed that bitter-tasting compounds modulate eating behaviour through bitter taste receptors in the gastrointestinal tract. This study aimed at evaluating the influence of microencapsulated bitter compounds on human appetite and energy intakes. A microencapsulated bitter ingredient (EBI) with a core of bitter Gentiana lutea root extract and a coating of ethylcellulose-stearate was developed and included in a vanilla microencapsulated bitter ingredient-enriched pudding (EBIP). The coating masked bitterness in the mouth, allowing the release of bitter secoiridoids in the gastrointestinal tract. A cross-over randomised study was performed: twenty healthy subjects consumed at breakfast EBIP (providing $100 \mathrm{mg}$ of secoiridoids) or the control pudding (CP) on two different occasions. Blood samples, glycaemia and appetite ratings were collected at baseline and 30, 60, 120 and $180 \mathrm{~min}$ after breakfast. Gastrointestinal peptides, endocannabinoids (EC) and $\mathrm{N}$-acylethanolamines (NAE) were measured in plasma samples. Energy intakes were measured at an ad libitum lunch $3 \mathrm{~h}$ after breakfast and over the rest of the day (post lunch) through food diaries. No significant difference in postprandial plasma responses of gastrointestinal hormones, glucose, EC and NAE and of appetite between EBIP and CP was found. However, a trend for a higher response of glucagon-like peptide-1 after EBIP than after CP was observed. EBIP determined a significant $30 \%$ lower energy intake over the post-lunch period compared with CP. These findings were consistent with the tailored release of bitter-tasting compounds from EBIP along the gastrointestinal tract. This study demonstrated that microencapsulated bitter secoiridoids were effective in reducing daily energy intake in humans.
\end{abstract}

Key words: Nutrient sensing: Bitter taste receptors: Satiety: Microencapsulation

The knowledge that cells with taste receptors are not only present in the mouth but are widely distributed in the human digestive tract (trachea, stomach, intestine, bile duct) boosted several research studies aimed at understanding the physiological roles of these taste circuits in humans ${ }^{(1)}$. Mounting evidence indicates that taste cells in the gastrointestinal (GI) tract play a major role in nutrient sensing and in triggering a specific gut-brain response ${ }^{(2)}$. In fact, taste receptor agonists elicit in enteroendocrine cells in vitro and in animals in vivo the release of peptides (including CCK, glucose-dependent insulinotropic peptide (GIP), peptide YY (PYY) and glucagon-like peptide-1 (GLP-1)), which are involved in the regulation of GI secretion and motility, glucose homoeostasis, food intake and satiety ${ }^{(3)}$. In particular, several studies on cell lines, animals and humans suggested that bitter-tasting compounds may modulate energy intake (EI) by delaying gastric emptying through the inhibition of gastric contractility and by triggering the secretion of CCK, GLP-1 and ghrelin ${ }^{(4-9)}$. In addition, a link between the bitter taste receptors and the endocannabinoids (EC) system, a group of molecules also involved in the regulation of energy homoeostasis and reward ${ }^{(10)}$, has been suggested. Tomassini Barbarossa et al. ${ }^{(11)}$ showed that the sensitivity to the bitter compound 6- $n$-propylthiouracil was associated with higher plasma levels of EC 2-arachidonoylglycerol (2-AG) and arachidonoylethanolamide (AEA). They speculated that the genetic of bitter taste receptors may influence the eating behaviour through the modulation of the EC system ${ }^{(11-12)}$.

Moreover, a long-term study conducted in high-fat-diet-fed rats demonstrated that isohumulones, the bitter compounds derived from hops in beer, improved insulin sensitivity and lipid

Abbreviations: EBIP, microencapsulated bitter ingredient-enriched pudding; EC, endocannabinoids; EI, energy intake; GI, gastrointestinal; GIP, glucosedependent insulinotropic peptide; GLP-1, glucagon-like peptide-1; PP, pancreatic polypeptide; PYY, peptide YY.

* Corresponding author: P. Vitaglione, fax +39 81 7762580, email paola.vitaglione@unina.it 
metabolism through activation of both PPAR- $\alpha$ and $-\gamma^{(13)}$. An effect of isohumulones in controlling glycaemia in mild diabetic subjects was also ascertained by the same authors and was confirmed by Obara et al. ${ }^{(14)}$. Contrasting results were found in the two studies on the ability of hop-derived bitter compounds to control body weight upon a 12 -week intervention ${ }^{(13,14)}$.

In these in vivo studies bitter compounds were always administered as gastric gavage or drugs in the form of capsules, in order to skip the natural aversion for this taste and possible anticipated physiological responses induced by oral tasting. In fact, the use of bitter compounds as food ingredients with specific health effects is limited by the general aversion for this taste. The aversion for bitter is not an intrinsic value of this tastant, but it comes from the ability of bitter compounds to stimulate the brain centre for disgust ${ }^{(15)}$. Mueller et al. ${ }^{(16)}$ clearly demonstrated that the attractive or aversive behaviour towards bitter compounds is mediated by the specific activation of taste receptors cells, rather than being a simple property of the tastant molecules ${ }^{(16)}$

On the other hand, social interactions may influence the food palatability, leading to the recognition of certain bitter foods, such as coffee or beer, as highly palatable ${ }^{(17)}$. Food palatability has a crucial role in eating behaviour. The relation between food palatability and appetite sensations or EI is not clear, but several studies demonstrated that hunger and food intakes increase as palatability increases ${ }^{(18)}$.

Encapsulation is a reliable strategy to design a palatable food enriched with functional compounds with unpleasant taste. The formation of a specific external coating around the desired compound avoids the perception in the mouth and allows the controlled delivery of the encapsulated compound to the different compartments of the GI tract ${ }^{(19)}$.

In this study a new food ingredient consisting of bitter compounds encapsulated with a coating material was developed. The core was a concentrated extract of Gentiana lutea root with a known amount of bitter compounds, and the coating was made of ethylcellulose and stearic acid. In this way, we aimed to mask bitterness in the mouth and obtain the release of the core material in the intestine. This ingredient was included in a vanilla pudding that was administered to volunteers to verify the hypothesis that it might influence appetite in humans. The appetite ratings, GI hormones, EC and $\mathrm{N}$-acylethanolamine (NAE) responses over $3 \mathrm{~h}$ from consumption of the new pudding and the control pudding (CP) (without encapsulated ingredient) as well as individual $24 \mathrm{~h}$ EI were recorded in healthy subjects on different experimental days.

\section{Methods \\ Encapsulated bitter ingredient}

An aqueous extract of $G$. lutea root was provided by Polcaro Fitopreparazioni SRL and was chemically characterised by HPLC analysis using the method described by Aberham et $a l .{ }^{(20)}$. Separation of the bitter compounds was achieved on a Zorbax Eclipse XDB-C18 column $(150 \times 4.6 \mathrm{~mm}, 5 \mu \mathrm{m}$; Agilent Technologies) using as mobile phases $0 \cdot 1 \%(\mathrm{v} / \mathrm{v})$ formic acid acidified water (A) and acetonitrile (B). The following binary gradient was used: $0 \mathrm{~min} 95 \mathrm{~A} / 5 \mathrm{~B}, 12 \mathrm{~min} 80 \mathrm{~A} / 20 \mathrm{~B}, 20 \mathrm{~min}$ $70 \mathrm{~A} / 30 \mathrm{~B}, 40 \mathrm{~min} 20 \mathrm{~A} / 80 \mathrm{~B}, 45 \mathrm{~min} 2 \mathrm{~A} / 98 \mathrm{~B}, 53 \mathrm{~min} 2 \mathrm{~A} / 98 \mathrm{~B}$, $53.5 \mathrm{~min} 95 \mathrm{~A} / 5 \mathrm{~B}$, and $65 \mathrm{~min} 95 \mathrm{~A} / 5 \mathrm{~B}$. Flow rate and injected sample volume were set at $1.0 \mathrm{ml} / \mathrm{min}$ and $20 \mu \mathrm{l}$, respectively. Detection was performed at $254 \mathrm{~nm}$. Identification and quantification of the secoiridoids was based on a calibration curve ranging from 0.5 to $50 \mathrm{mg} / \mathrm{l}$. In order to mask bitterness in the mouth and to allow the release of bitter compounds in the intestine, the gentian root extract was submitted to spray-drying technique and coated with ethylcellulose and stearate coating following the procedure described by Shirai et $a l .{ }^{(21)}$.

\section{Puddings}

Two equally isoenergetic and macronutrient-enriched vanilla puddings were formulated: a microencapsulated bitter ingredientenriched pudding (EBIP) and a CP. EBIP contained $1.25 \mathrm{~g}$ of micro encapsulated bitter ingredient (EBI) per a $100 \mathrm{~g}$ portion, providing $100 \mathrm{mg}$ of bitter secoiridoids. CP contained the same amount of EBI coating except the bitter core. The two puddings were also very similar for sensory properties as assessed by a preliminary test conducted with volunteers (data not shown). In order to provide about $20 \%$ of the total daily EI three biscuits were served together with the CP or the EBIP at breakfast. The macronutrient composition, energy values and bitter compound content of the two puddings and breakfasts are reported in Table 1.

\section{In vitro digestion of puddings and cryo-scanning electron microscopy analysis}

The stability of EBI along the GI tract from the oral cavity up to the intestine was tested by a multistep enzyme in vitro digestion-simulating human digestive process. A volume of $5 \mathrm{~g}$ of EBIP and CP was submitted to the in vitro digestion protocol described by Papillo et $a l^{(22)}$ and $20 \mu$ of the soluble extract from the salivary phase and from the gastrointestinal phase (after sequential treatment of the food samples with pepsin, pancreatin, $\alpha$-amylase, pronase and viscozyme) was analysed using ultra-high-resolution (cryo) scanning electron microscopy (SEM). In brief, the samples were pipetted onto anodisc filters, which were placed onto standard filter paper. After draining most of the liquid the anodisc filter was placed on a SEM sample holder using a thin layer of carbon glue (Leit-C; Neubauer

Table 1. Nutritional composition and bitter compounds content of the two puddings (micro encapsulated bitter ingredient (EBI) - pudding and control pudding), biscuits and of the breakfasts offered to volunteers

\begin{tabular}{lccccc}
\hline & $\begin{array}{c}\text { EBI } \\
\text { pudding }\end{array}$ & $\begin{array}{c}\text { Control } \\
\text { pudding }\end{array}$ & & $\begin{array}{c}\text { EBI } \\
\text { Biscuits }\end{array}$ & $\begin{array}{c}\text { Control } \\
\text { breakfast } \\
\text { breakfast }\end{array}$ \\
\hline Carbohydrates (g) & $9 \cdot 5$ & $9 \cdot 5$ & $35 \cdot 6$ & $45 \cdot 1$ & $45 \cdot 1$ \\
Protein (g) & $5 \cdot 5$ & $5 \cdot 5$ & $3 \cdot 2$ & $8 \cdot 7$ & $8 \cdot 7$ \\
Fat (g) & $0 \cdot 2$ & $0 \cdot 2$ & $10 \cdot 4$ & $10 \cdot 6$ & $10 \cdot 6$ \\
Energy (kJ) & 259 & 259 & 1054 & 1314 & 1314 \\
Energy (kcal) & 62 & 62 & 252 & 314 & 314 \\
Bitter compounds (mg) & 100 & - & - & 100 & - \\
\hline
\end{tabular}


Chemikalien). The samples were then immediately frozen in liquid $\mathrm{N}_{2}$. The samples were transferred to a non-dedicated cryo-preparation system (MED 020/VCT 100; Leica) onto a sample stage at $-93^{\circ} \mathrm{C}$. In this cryo-preparation chamber the samples were freeze-dried for $2 \mathrm{~min}$ at $-93^{\circ} \mathrm{C}$ at $1.3 \times 10-6$ mbar to remove water vapour contamination. Thereafter, the samples were sputter-coated with a layer of $10 \mathrm{~nm}$ Tungsten. The samples were cryo-shield-transferred into the field emission scanning microscope (Magellan 400; FEI) on the sample stage at $-125^{\circ} \mathrm{C}$. The analysis was performed with SE detection at $2 \mathrm{kV}, 6 \mathrm{pA}$.

\section{Subjects}

Recruitment was performed at the Department of Agricultural Sciences of the University of Naples among students and staff of the department. Subjects were excluded from the study if they had a $\mathrm{BMI} \geq 25 \mathrm{~kg} / \mathrm{m}^{2}$, any chronic illnesses such as diabetes or hypertension, if they were smokers or were taking any prescription medication, were under a controlled dietary regimen or had lost weight over the previous 3 months, or were pregnant or lactating. A total of twenty subjects were recruited and enrolled in two experimental sessions. Subject characteristics are reported in Table 2 .

\section{Study design}

This study was conducted according to the guidelines laid down in the Declaration of Helsinki, and all procedures involving human subjects/patients were approved by the Ethical Committee of the University of Naples (protocol no. 235/13). Written informed consent was obtained from all subjects.

The study had a two-sided cross-over randomised design with a 1 -week wash-out period. Thus each subject participated in two 1-d experimental sessions. On the evening before the experimental days volunteers were instructed to consume a standardised dinner until 22.00 hours. On the experimental days fasted subjects arrived at 08.15 hours to the nutritional laboratory of the Department of Agricultural Sciences. After $10 \mathrm{~min}$ they rated their appetite sensations (hunger, fullness, satiety and desire to eat) on a $100 \mathrm{~mm}$ visual analogue scale, anchored on the left as 'not at all' and on the right as 'extremely'. Subsequently, a venous catheter was placed into an arm vein and a baseline blood sample was collected and glycaemia was measured by finger-pricking. A duration of 30, 60, 120 and $180 \mathrm{~min}$ after subjects had consumed their breakfast

Table 2. Subjects' characteristics

(Mean values and standard deviations)

\begin{tabular}{lccc}
\hline & Mean & SD & Range \\
\hline Number (M/F) & $20(11 / 9)$ & - & \\
Age (years) & 25.3 & $5 \cdot 1$ & $20-36$ \\
Height $(\mathrm{m})$ & 1.66 & $0 \cdot 1$ & $1 \cdot 55-1 \cdot 78$ \\
Weight $(\mathrm{kg})$ & 64.4 & $9 \cdot 7$ & $55-84$ \\
BMl $\left(\mathrm{kg} / \mathrm{m}^{2}\right)$ & 22.1 & $2 \cdot 3$ & $18 \cdot 5-24 \cdot 4$ \\
\hline
\end{tabular}

M, male; F, female. (in $15 \mathrm{~min}$ ), appetite sensations, glycaemia and blood samples were collected. At $3 \mathrm{~h}$ post-breakfast an ad libitum lunch was offered to the volunteers who were free to take all the time they wanted to consume a self-selected meal. During the lunch each subject sat in a single-place cabin separated by the others, and EI was measured as the differences between the amount of food contained in each plate taken and the foods left in the plate by the subject. Before leaving the laboratory, subjects were asked to fill out a food diary over the following $24 \mathrm{~h}$ to register all foods and beverages consumed, together with the post-ingestive sensations.

\section{Test meal}

The food offered in the test meal included a variety of typical Italian dishes: pasta with tomato sauce, pasta with zucchini, bread, fish, chicken cutlet, fries, salad and fruit. They were chosen on the basis of a food preference questionnaire filled out during the enrolment procedure: those not rated by participants as very high or very low in a hedonic scale from 0 to 10 were selected. The dishes were prepared following the same recipes always in order to accurately know the energy value and the macronutrient composition. Food was portioned in coded plates and subjects were free to compose their tray and eat ad libitum.

\section{Biochemical analysis}

Blood collection. For each time point, two different vacutainer ${ }^{\circledR}$ tubes of $4 \mathrm{ml}$ each were used to collect plasma samples. A protease inhibitor mix, consisting of dipeptidyl peptidase IV (DPPIV) inhibitor (Millipore's DPPIV inhibitor; St Charles), protease inhibitor cocktail (Sigma) and 4-(2-Aminoethyl)-benzenesulfonyl fluoride hydrochloride (Pefabloc ${ }^{\circledR}$ SC; Roche Diagnostics), was immediately added to the blood sample destined for identifying the GI peptide. After sample preparation, tubes were centrifuged at $4000 \boldsymbol{g}$ for $10 \mathrm{~min}$ and plasma samples were aliquoted and frozen at $-80^{\circ} \mathrm{C}$ within $30 \mathrm{~min}$ from collection.

Gastrointestinal peptides. Luminex Technology (Bio-Plex; Bio-Rad) was used to determine GI peptides. A magnetic bead panel kit provided by Milliplex ${ }^{\circledR}$ (Merck Millipore; Millipore S.p.A.) allowed the simultaneous determination of the following nine hormones: ghrelin, glucagon, GLP-1, GIP, insulin, leptin, pancreatic polypeptide (PP), total amylin and PYY. The sensitivity levels of the assay (ng/l) were: ghrelin 2.0; leptin, 27.0; GIP 0.6; GLP-1 7.0; glucagon 6.0; insulin 58.0; PP 2.0; total amylin 14.0; PYY 8.0.

The intra-assay variation (\%CV) was $2 \%$ for ghrelin, total amylin and PYY; 3\% for GIP, glucagon, insulin and leptin; $4 \%$ for the PP; and $7 \%$ for the GLP- 1 . The inter-assay variation (\%CV) was $4 \%$ for leptin; $5 \%$ for GIP; $6 \%$ for insulin; $7 \%$ for PP and glucagon; $8 \%$ for ghrelin; 10\% for GLP-1; $11 \%$ for PYY; and 33\% for amylin.

Endocannabinoids and $\mathrm{N}$-acylethanolamines. Two EC 2-arachidonoylglycerol (2-AG) and AEA - and three NAE linoleoyl ethanolamide (LEA), oleoylethanolamide (OEA) and palmitoylethanolamide (PEA) - were determined by LC/MS/MS.

Samples were extracted following the method set up by Lam et $a l^{(23)}$. In brief, $1 \mathrm{ml}$ of sample was added into Oasis HLB 
$1 \mathrm{cc}, 30 \mathrm{mg}$ cartridges (Waters) preconditioned with $1 \mathrm{ml}$ methanol and $1 \mathrm{ml} \mathrm{H}_{2} \mathrm{O}$. The cartridges were washed with $1 \mathrm{ml}$ $40 \%$ aqueous methanol and eluted in $1 \mathrm{ml}$ acetonitrile. The eluants were then dried under $\mathrm{N}_{2}$, and re-suspended in $100 \mu \mathrm{l}$ of acetonitrile-water (1:1) before chromatographic separation ${ }^{(23)}$.

This was performed using an HPLC apparatus equipped with two micropumps Perkin-Elmer series 200. A Synergi Max RP 80 column, $50 \times 2 \cdot 1 \mathrm{~mm}$ (Phenomenex), was used and the flow rate was set to $0.2 \mathrm{ml} / \mathrm{min}$. Injection volume was $20 \mu \mathrm{l}$. MS/MS analyses were performed on an API 3000 triple quadrupole MS (Applied Biosystems). All analyses were performed with a TurboIonSpray (Applied Biosystems) source set as previously described ${ }^{(24)}$. The acquisition was carried out in multiple reaction monitoring in positive ion mode for each compound. Data acquisition and processing were performed using Analyst software, version 1.4. Acquisition parameters have been already published $^{(24)}$.

Blood glucose. Blood glucose concentration was measured by finger pricking and using a bedside glucometer (OneTouch Sure Step; LifeScan Inc.). Accuracy of the glucometer was evaluated by the manufacturer using least-squares linear regression analysis and was found to be $98 \%$ 'clinically accurate' when compared with the reference.

\section{Statistical analysis}

The sample size needed to detect an effect of breakfast was estimated on the basis of previous studies. For the primary endpoint, power analysis indicated that a sample size of seventeen participants was sufficient to detect a minimum difference of $837 \mathrm{~kJ}(200 \mathrm{kcal})$ in EI with a power of $80 \%$ and an $\alpha=0.05^{(25)}$. Regarding the secondary outcomes (biochemical parameters) a sample size of thirteen participants was calculated to be adequate to find significant differences ${ }^{(24)}$. Therefore, the participant number was increased to twenty because of possible dropouts. ANOVA was performed to exclude any difference at baseline between treatments for both biochemical analysis and appetite scores. Because no differences were found the results were analysed and expressed as the absolute changes from the baseline to reduce possible effects of intersubject fasting variability. The subjective appetite sensations and the response of hormones and EC were tested for the effect of treatment and of time as factors by ANOVA for repeated measures. The linear trapezoidal rule was used to calculate the total AUC for the appetite sensations and biochemical markers. Differences in EI after the two test meals were assessed using paired $t$ test analysis. Results are expressed as means with their standard errors and were considered statistically significant for $P<0 \cdot 05$. Statistical analyses were performed using the Statistical Package for Social Sciences (version 16.0; SPSS Inc.).

\section{Results}

Encapsulated ingredient characterisation and in vitro digestion of puddings

An EBI containing $8 \%$ of bitter compounds (including loganic acid $11.5 \%$, swertiamarin $9.5 \%$, gentiopicroside $53.9 \%$, sweroside $25 \cdot 1 \%$ as shown in Fig. 1) was obtained and used in pudding preparation. The EBIP could not be distinguished by the $\mathrm{CP}$ as assessed by a preliminary test conducted with volunteers (data not shown). The results from the in vitro digestion of the puddings combined with the cryo SEM technique analysis confirmed that EBI was stable during the salivary phase, whereas it lost the physical form along the GI tract during the digestion steps (Fig. 2), thus allowing the delivery of the bitter compound-rich core.

\section{Appetite}

Fig. 3 shows the profiles of appetite sensations over $180 \mathrm{~min}$ after breakfasts. All the sensations positively (for fullness and satiety) or negatively (for hunger and desire to eat) peaked at $30 \mathrm{~min}$ and returned to baseline values at $180 \mathrm{~min}$ after breakfasts. $A_{U-180}$ of each sensation was not significantly different after EBIP or CB consumption, being 3229 (SEM 1123) v. 1861 (SEM 863) $\mathrm{mm} \times \min$ for fullness, 3800 (SEM 1230) $v .2648$ (SEM 1176) $\mathrm{mm} \times \mathrm{min}$ for satiety, -2999 (SEM 810) $v$. -3550 (SEM $1107) \mathrm{mm} \times \mathrm{min}$ for hunger and -2558 (SEM 805) $v$. -2444 (SEM 1073) $\mathrm{mm} \times$ min for desire to eat ( $P>0.05$ each).

\section{Energy intake}

Fig. 4 shows the EI at the ad libitum lunch and over the rest of the experimental day. When subjects had EBIP at breakfast compared with CP, a non-significant $10 \%$ lower EI at lunch (3443 (SEM 364) v. 3812 (SEM 230) kJ ((823 (SEM 87) v. 911 (SEM $55) \mathrm{kcal}), P>0.05)$ but a significant $30 \%$ lower EI during the post-lunch time period (2494 (SEM 264) v. 3548 (SEM 414) kJ ((596 (sem 63) v. 848 (sem 99) kcal), $P=0.04$ ) was recorded. This caused a $22 \%$ lower $24 \mathrm{~h}$ EI during the experimental day with EBIP than with CP (5937 (SEM 473) v. 7360 (SEM 506) kJ ((1419 (SEM 113) $v .1759$ (SEM 121) kcal); $P<0.05)$. No differences were found in the macronutrient composition of lunch and post-lunch meals between the 2 experimental days.

\section{Blood glucose}

Blood glucose response over $180 \mathrm{~min}$ after breakfasts was monitored. A significant increase at $30 \mathrm{~min}$ following both breakfasts compared with baseline was found. At $60 \mathrm{~min}$ blood glucose concentration reduced and returned to baseline values at $180 \mathrm{~min}$. No significant differences between treatments were found, with $\mathrm{AUC}_{0-180}$ being 179.47 (SEM 8.22) v. 186.75 (SEM 6·16) $\mathrm{g} / 1 \times \min$ for $\mathrm{CP}$ and $\mathrm{EBIP}$, respectively.

\section{Gastrointestinal peptides}

Amylin, ghrelin, glucagon, GIP, insulin, leptin, PP, PYY and GLP-1 variations from baseline over the $3 \mathrm{~h}$ following breakfast are reported in Fig. 5. At $30 \mathrm{~min}$ after both breakfasts ghrelin concentration showed a significant reduction $(P<0 \cdot 05)$, whereas amylin, GIP, insulin and PP increased $(P<0.05)$ compared with baseline. Interestingly, at $30 \mathrm{~min}$ GLP-1 significantly peaked only after EBIP consumption $(P<0.05)$. All the hormones, with the exception of PP and GIP, returned to baseline levels within $180 \mathrm{~min}$ 
(a)

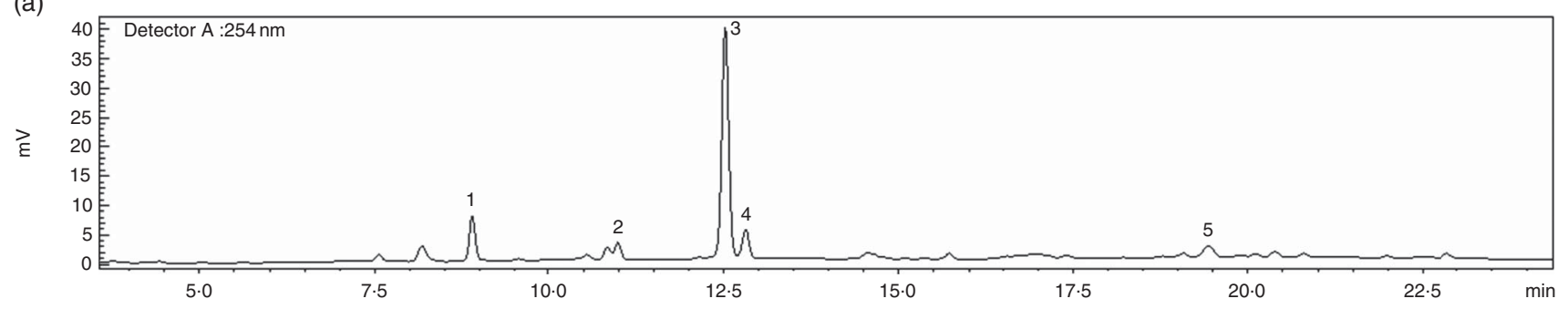

(b)

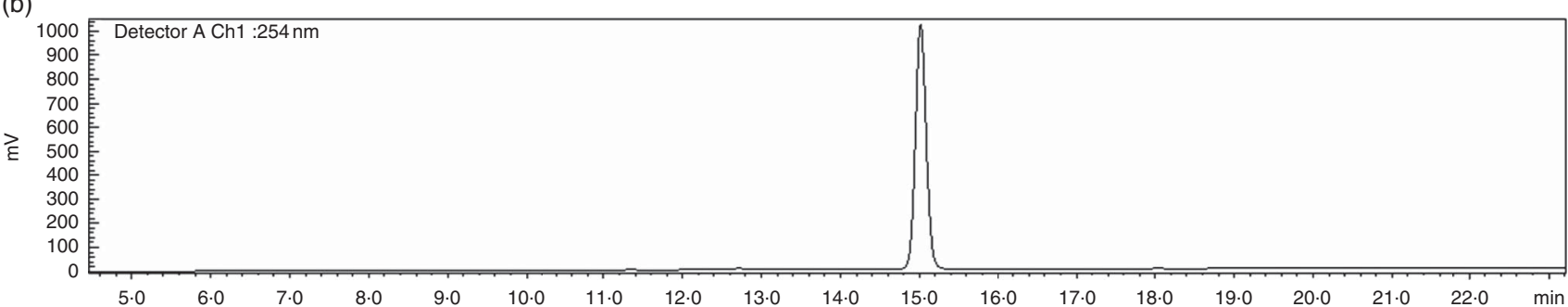

(c)

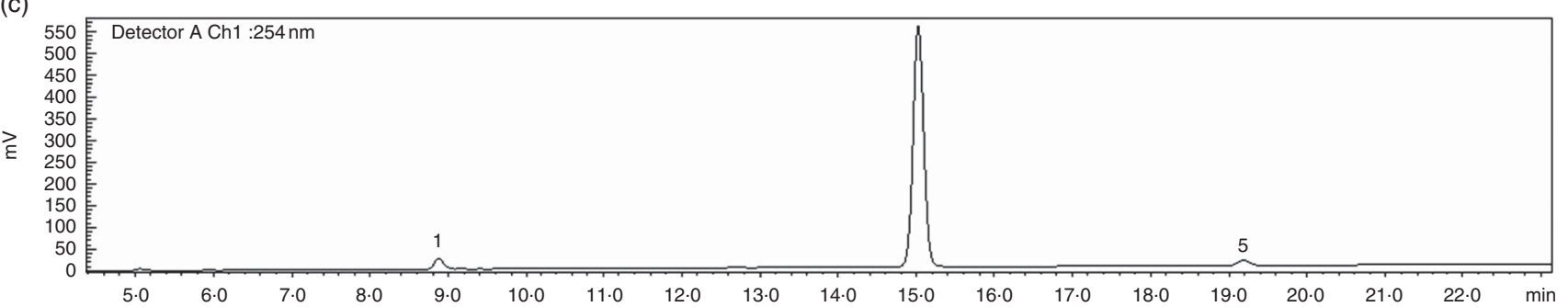

Fig. 1. HPLC profile of secoiridoids present in the Gentiana lutea aqueous extract. (a) Gentiana lutea root aqueous extract. (b) Microencapsulated Gentiana lutea aqueous root extract after the salivary phase of the in vitro enzyme digestion. (c) Microencapsulated Gentiana lutea aqueous extract after the intestinal phase of the in vitro enzyme digestion. 1, loganic acid; 2, swertiamarin; 3, gentiopicroside; 4, sweroside; 5, amarogentin.

after the breakfasts. Glucagon, leptin and PYY did not change after any breakfast. No significant differences between the two experimental breakfasts were found for any of the hormones investigated. Interestingly, a trend for a higher response of GLP-1 after EBIP than after $\mathrm{CP}$ was found $\left(\mathrm{AUC}_{0-180}\right.$ after EBIP was $14660 \mathrm{ng} \times \mathrm{min} / \mathrm{l}$ and after $\mathrm{CP}$ was $10553 \mathrm{ng} \times \mathrm{min} / \mathrm{l}, P=0 \cdot 09)$.

\section{Endocannabinoids and $\mathrm{N}$-acylethanolamines}

A significant decrease from baseline of plasma levels of AEA, LEA, OEA and PEA over the $3 \mathrm{~h}$ after both breakfasts was found $(P<0 \cdot 05) .2-A G$ showed a significant reduction from baseline only at $180 \mathrm{~min}$ after both breakfasts. No differences between the plasma response of any EC or NAE after the two puddings were recorded (Fig. 6).

\section{Discussions}

Some in vitro and in vivo studies showed that the activation of bitter receptors in the GI tract may result in the secretion of hormones modulating appetite and eating behaviour ${ }^{(4-9)}$. This study was designed to assess the efficacy of microencapsulated bitter compounds to modulate appetite and EI in humans. A new food ingredient consisting of a microencapsulated G. lutea root extract was developed and included in a palatable vanilla pudding, which was sensory comparable to the control one.

G. lutea bitterness is due to the secoiridoids monoterpenes and their acylglucoside derivatives such as amarogentin, which is known as one of the most bitter among natural compounds ${ }^{(26)}$. Microencapsulation of the extract by a lipid-based material was used to mask the bitterness of $G$. lutea secoiridoids in the mouth and to guarantee their release in the intestine upon consumption of the pudding containing EBI.

Pudding was chosen as the test food because during its preparation ingredients never reach a temperature $>60^{\circ} \mathrm{C}$ and only slow agitation is necessary: in this way the stability of EBI in the final product was guaranteed. On the other hand the enrichment of EBIP with $1 \%$ EBI was selected on the basis of a previous study from our research group demonstrating that $100 \mathrm{mg}$ of bitter secoiridoids from $\mathrm{G}$. lutea extract was effective in reducing the plasma levels of orexigenic endocannabinoid 2-AG in humans upon a modified sham feeding protocol ${ }^{(27)}$.

Data from the present study indicated that the consumption of EBIP at breakfast did not influence EI at lunch offered $3 \mathrm{~h}$ after its consumption, but it led to a $30 \%$ reduced EI over the post-lunch period compared with CP.

These results were partially in agreement with those of Janssen et al. ${ }^{(7)}$ who reported that gastric administration of bitter compounds in mice determined an immediate release of ghrelin and an increase in food intake accompanied by an anorexigenic 

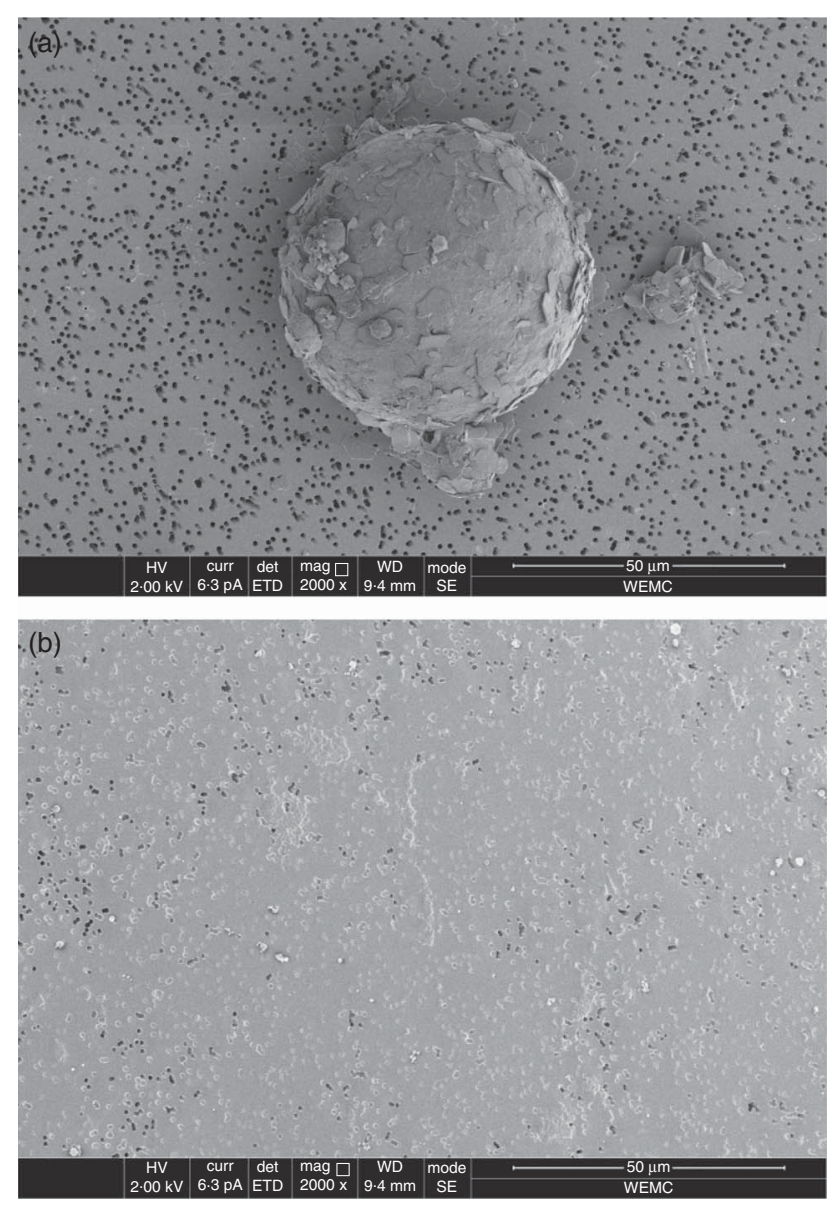

Fig. 2. Scan sight of the solubilised material from microencapsulated bitter ingredient-enriched pudding in vitro digestion. The microcapsules were visible and intact in the salivary phase (a) whereas they were absent in the material solubilised after the gastrointestinal enzyme digestion (b).

effect starting from the next $4 \mathrm{~h}$ after treatment (resulting in a $49 \%$ reduction in $24 \mathrm{~h}$ food intake in mice treated with bitter compounds compared with placebo). In that study the food intake reduction was also associated with an inhibition of gastric emptying, which was not mediated by cholecystokinin and GLP-1, but involved a direct inhibitory effect of bitter compounds on gastric contractility mediated by ion channel mechanisms ${ }^{(7)}$. The capacity of intragastric administration of bitter solutions to delay gastric emptying was recently confirmed in pigs $^{(8)}$ and fasting humans ${ }^{(28)}$, whereas it did not underpin the reduction of appetite over $4 \mathrm{~h}$ post consumption of a meal ingested 30 min after bitter administration ${ }^{(29)}$

The uniqueness of our study was the use of microencapsulated gentian extract (EBI). It allowed us to evaluate the effect of bitter-tasting compounds on appetite and on eating behaviour in humans in a physiological condition and in a less stressful manner than in previous studies using nasogastric administration $^{(28,29)}$. In fact, the use of microencapsulated bitter compounds possessing a taste-masking effect prevented any adverse GI events or nausea in volunteers and influenced their eating behaviour following EBIP.

Behavioural and biochemical data collected over the $3 \mathrm{~h}$ after breakfast showed a parallel $10 \%$ (not significant) reduction of
EI at lunch and a slight $28 \%$ (not significant) increase in plasma GLP-1 response after EBIP compared with CP. This finding was likely due to the EBI that had already reached the duodenum over the time period between breakfast and lunch, because it is known that in healthy subjects about $60 \%$ of a solid meal is reversed in the duodenum over $3 \mathrm{~h}$ from eating ${ }^{(30)}$. Thus, in accordance with the working mechanism designed for EBI, this finding suggested that once in the duodenum EBI digestion allowed the release of the bitter core (amarogentin and the other bitter secoiridoids) from the microcapsules ${ }^{(31)}$ and it could trigger the secretion of GLP-1 from the enteroendocrine cells.

Several in vitro studies supported this hypothesis. Stimulation of GLP-1 secretion was induced by bitter compounds in mouse STC-1 and human NCIeH716 enteroendocrine cell lines when treated with TAS2R agonist ${ }^{(6,32,33)}$. Among bitter compounds with this property loganic acid, a bitter iridoid glycoside isolated from G. scabra and present in EBI, was found ${ }^{(34)}$. Moreover, $G$. lutea bitter compounds were demonstrated to be able to bind several TAS2R including TAS2R1, $-4,-39,-43,-46,-47$ and $-50^{(35)}$.

On the other hand the significant $30 \%$ reduction in EI over the post-lunch period and the $22 \%$ reduction within the $24 \mathrm{~h}$ following EBIP consumption also demonstrated that a longer time than $3 \mathrm{~h}$ was necessary to benefit from the EI control effect of EBI (providing $100 \mathrm{mg}$ secoiridoids) when consumed in a semisolid food (pudding) and together with other solid foods in a real meal (like the breakfast of this study). Thus the fact that other mechanisms such as delayed gastric emptying mediated by interaction of bitter compounds with ions channels could co-work with GLP-1-mediated anorexigenic effect could not be excluded.

The evidence from this study is apparently contradictory to the common tradition of drinking bitter herb infusions to aid digestion or the popular use of bitter wines as aperitifs, leading to a short-term increase in appetite. Actually it is true that the activation of bitter receptors in the GI tract stimulates ghrelin secretion, resulting in a short-term orexigenic effect ${ }^{(7)}$; however, its release is predominant in the stomach ${ }^{(36)}$. This action was abolished in the experimental conditions adopted here as the lipid-based EBI coating was resistant to the hydrolytic environment of the stomach. This was in agreement with the study by Andreozzi et $a l .{ }^{(9)}$, in which the use of acid-resistant capsules containing $18 \mathrm{mg}$ of hydrochloride quinine did not affect ghrelin levels.

Data altogether suggested that when bitter compounds are masked to bitter receptors in the stomach (due to coating material or because they are included in a food or a meal) ghrelin secretion is reduced; therefore, over the day a longterm anorexigenic effect is prevalent on the short-term orexigenic effect.

The present study has some limitations as well. First, subjects participated in two randomised 1-d experimental sessions wherein they consumed a EBIP and a CP, once each, during breakfast. Therefore, it could not be excluded that some adaptive mechanisms would emerge and disrupt the maintenance of the effect over time during a continued consumption of EBIP. This point is central from an industry perspective to 
(a)

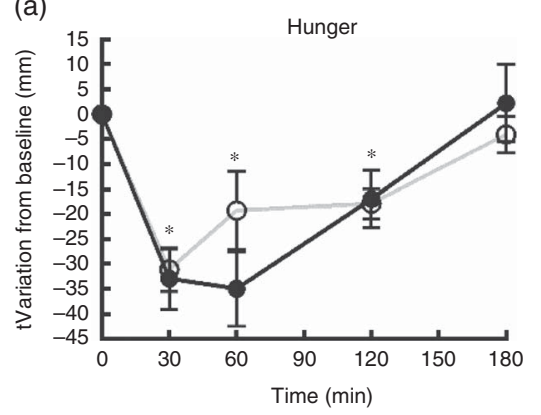

(c)

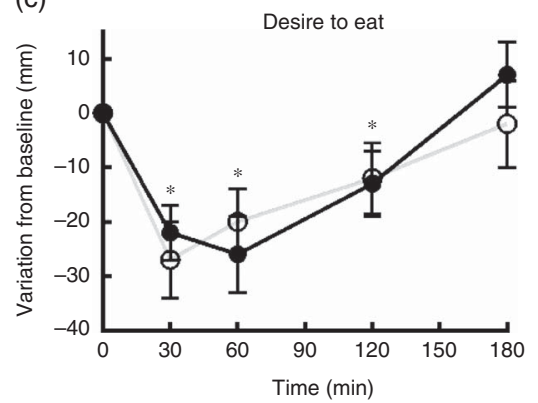

(b)

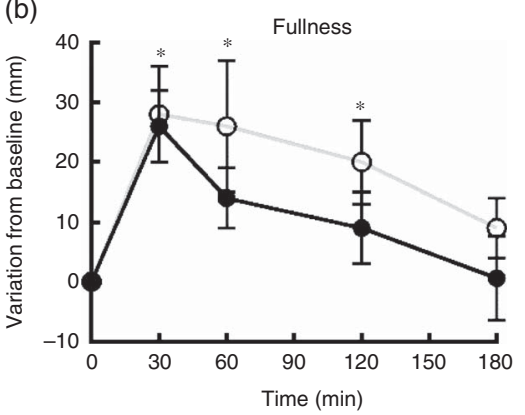

(d)

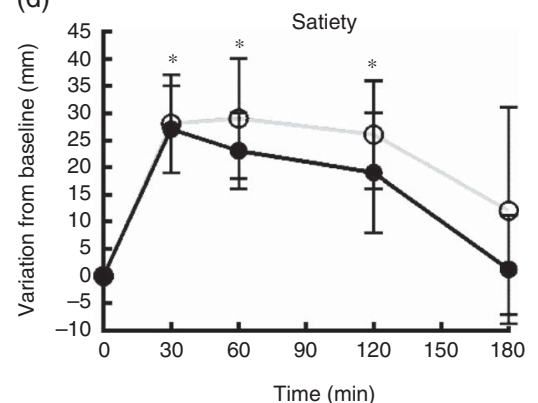

Fig. 3. Time course of the appetite sensations over the $3 \mathrm{~h}$ post-breakfast: (a) hunger; (b) fullness; (c) desire to eat; (d) satiety. Values are mean variations from baseline, with their standard errors. No differences were found between the two experimental conditions. ${ }^{*} P<0.05 v$. baseline (ANOVA for repeated-measures). - - microencapsulated bitter ingredient-enriched pudding; $\mathrm{O}$, control pudding.

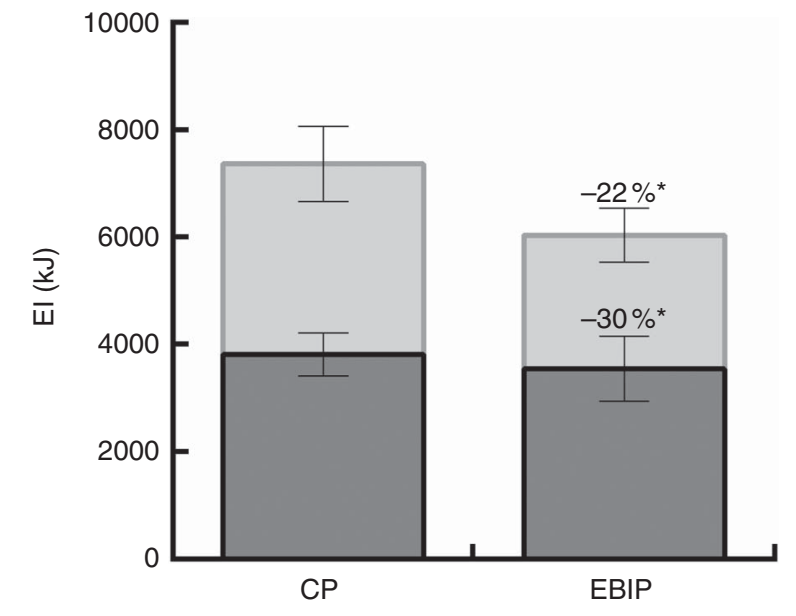

Fig. 4. Energy intakes (EI) at ad libitum lunch, over the remaining part of the experimental day (post-lunch) and total daily El (sum of lunch and post-lunch El) after breakfast with microencapsulated bitter ingredient-enriched pudding (EBIP) or control pudding (CP). Values are means, with their standard errors. ${ }^{\star} P<0.05 \mathrm{v}$. El at lunch and daily El after CP (paired $t$ test). $\square$, El post-lunch; $\square$, El lunch.

label an ingredient or food with a claim on satiety, as demonstrated by the failure of several satiety claim submissions to the European Food Safety Authority to be approved because of a lack of evidence that satiety generated by the product reduces EI and/or that the effect is sustained with repeated experience $^{(37,38)}$. Thus, further studies are warranted to verify whether EBIP may sustain EI control over a longer period. Second, the protocol used was primarily designed to verify the effect of EBI on EI in a real-life situation and it did not allow us to ascertain the physiological mechanisms underpinning its activity, which could be only hypothesised on the basis of the biochemical data collected over the $3 \mathrm{~h}$ post breakfast and on the basis of previous literature. It could not be ruled out that multiple mechanisms including delayed gastric emptying (mediated by gut hormones or ions channels) or direct effect of anorexigenic hormones co-worked over the $24 \mathrm{~h}$ from EBI consumption to determine its EI control effect.

\section{Conclusions}

In conclusion, the present study demonstrated that microencapsulation of bitter compounds designed to mask the bitter taste in the mouth and to allow a targeted delivery to the intestine is an effective approach to produce new food ingredients to control EI. These data, together with those from previous studies, suggested that the kinetic of bitter compound delivery along the GI tract is effective in modulation of appetite behaviour finalised to EI reduction in humans.

However, further studies aiming at clarifying the biochemical response underpinning the long-term effect on daily food intake here shown with EBI are warranted to model the kinetic of the delivery of bitter compounds to the GI tract. Modelling the delivery of bitter compounds in the light of physiological effects may be important to foresee the effect of the ingredient on body weight control in overweight subjects upon continued consumption. 
(a)

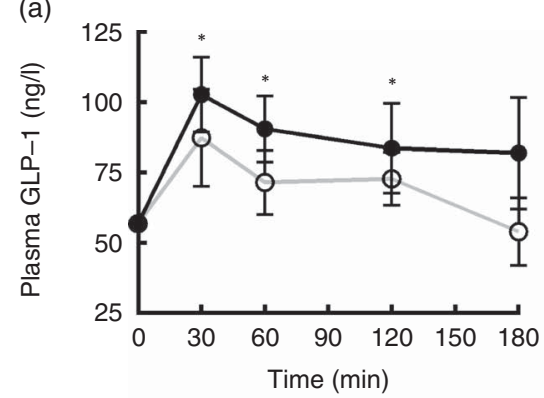

(c)

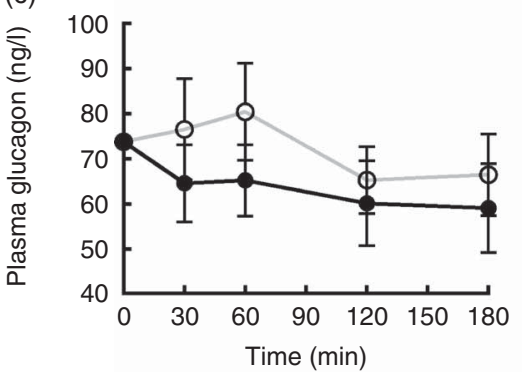

(e)

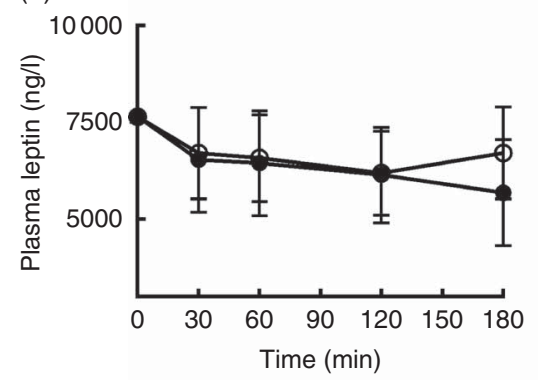

(g)

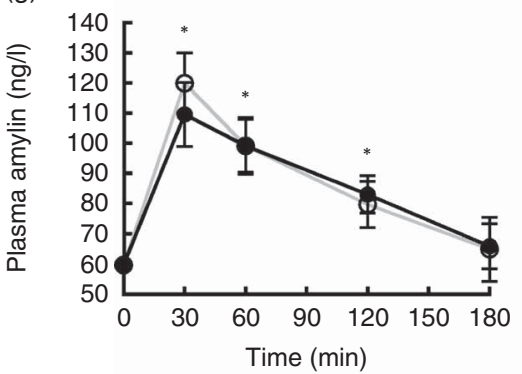

(i)

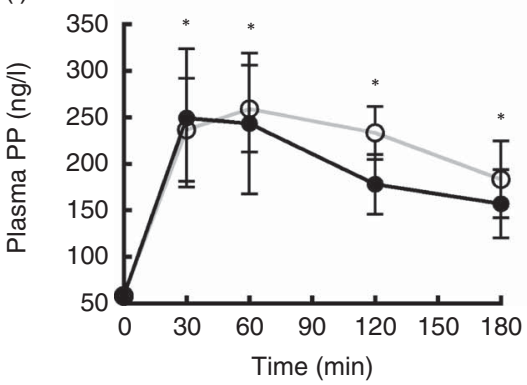

(b)

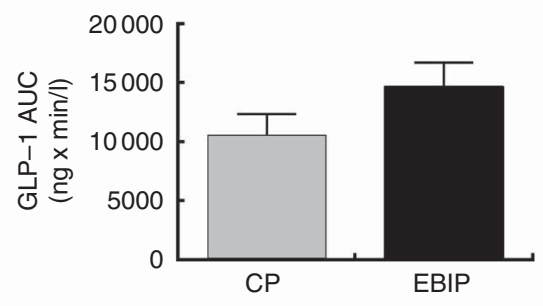

(d)

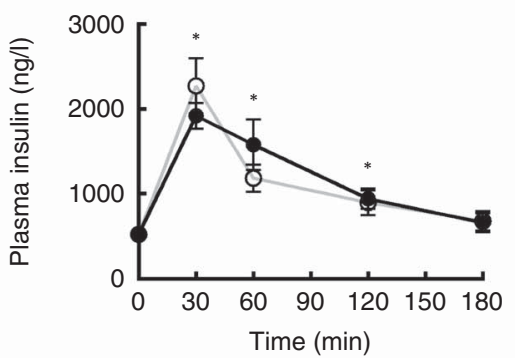

(f)

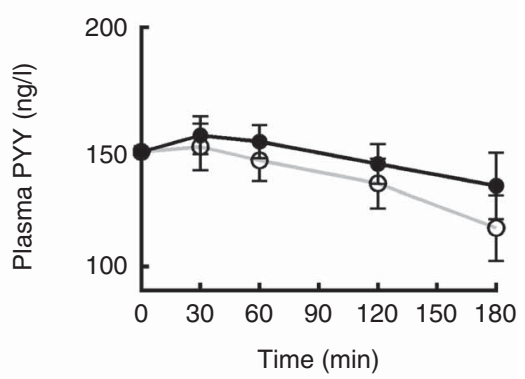

(h)

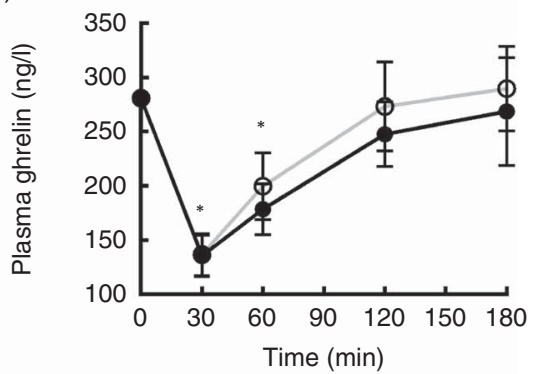

(j)

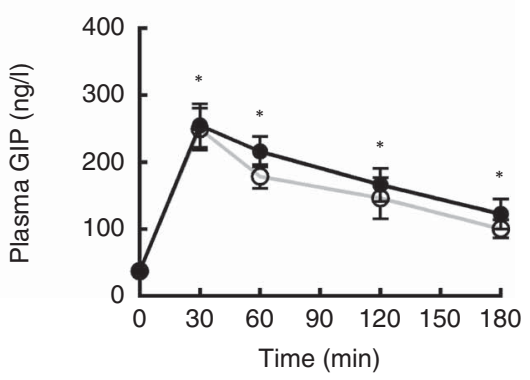

Fig. 5. Gastrointestinal hormone variations in plasma over the $3 \mathrm{~h}$ post-breakfasts: (a) glucagon-like peptide-1 (GLP-1); (b) AUC of GLP-1; (c) glucagon; (d) insulin; (e) leptin; (f) peptide YY (PYY); (g) amylin; (h) ghrelin; (i) pancreatic polypeptide (PP); (j) glucose-dependent insulinotropic peptide (GIP). Values are mean variations from baseline, with their standard errors. ${ }^{*} P<0.05 \mathrm{v}$. baseline (ANOVA for repeated-measures). EBIP, microencapsulated bitter ingredient-enriched pudding ( -2 ); $\mathrm{CP}$, control pudding $(-\mathrm{O})$. 
(a)

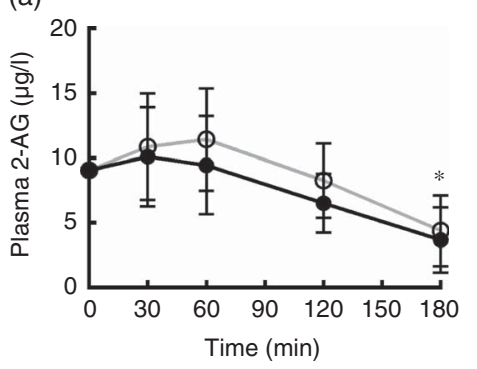

(b)

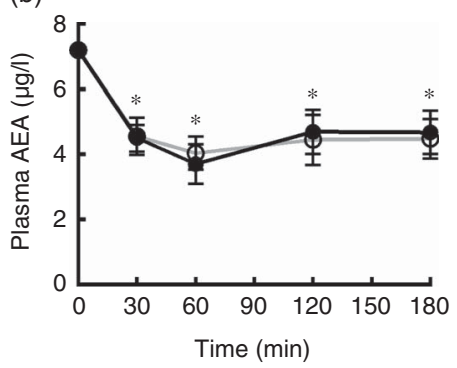

(c)

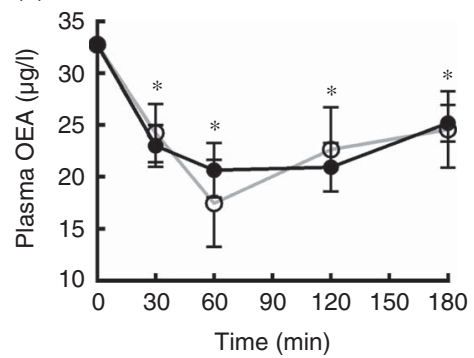

(d)

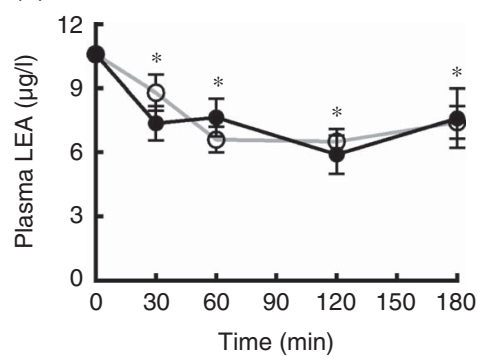

(e)

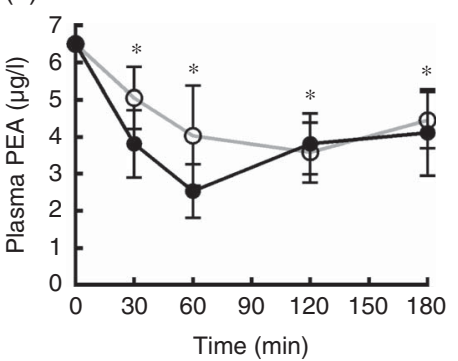

Fig. 6. Endocannabinoids and $N$-acylethanolamines variations in plasma over the $3 \mathrm{~h}$ post-breakfasts: (a) 2-arachidonoylglycerol (2-AG); (b) arachidonoylethanolamide (AEA); (c) oleoylethanolamide (OEA); (d) linoleoyl ethanolamide (LEA); (e) palmitoylethanolamide (PEA). Values are mean variations from baseline, with their standard errors. ${ }^{*} P<0.05 \mathrm{v}$. baseline (ANOVA for repeated-measures). EBIP, microencapsulated bitter ingredient-enriched pudding $(--)$; CP, control pudding $\left(-\mathrm{O}^{-}\right.$.

\section{Acknowledgements}

This study was supported by the programme PON01_ 02863 'Incapsulazione di principi attivi per il miglioramento di qualità e sicurezza degli alimenti' funded by the Italian Ministry of Education, University and Research. P. V. thanks Attilio Visconti for his skillful technical assistance during the study.

The authors' contributions are as follows: P. V. designed the study; M. A. and F. P. developed the encapsulated bitter ingredients; I. M. conducted the research; R. F. analysed biochemical samples; I. M. analysed questionnaires and performed the statistical analysis; I. M., V. F. and P. V. wrote the paper; P. V. had primary responsibility for the final content. All authors read and approved the final manuscript.

The authors have nothing to disclose.

\section{References}

1. Trivedi BP (2012) Hardwired for taste. Nature 486, S7-S9.

2. Rønnestad I, Akiba Y, Kaji I, et al. (2014) Duodenal luminal nutrient sensing. Curr Opin Pharmacol 19, 67-75.

3. Sternini C, Anselmi L \& Rozengurt E (2008) Enteroendocrine cells: a site of 'taste' in gastrointestinal chemosensing. Curr Opin Endocrinol Diabetes Obes 15, 73-78.

4. Chen MC, Wu SV, Reeve JR Jr, et al. (2006) Bitter stimuli induce $\mathrm{Ca} 2+$ signaling and CCK release in enteroendocrine STC-1 cells: role of L-type voltage-sensitive $\mathrm{Ca} 2+$ channels. Am J Physiol Cell Physiol 291, 726-739.

5. Dotson CD, Zhang L, Xu H, et al. (2008) Bitter taste receptors influence glucose homeostasis. PLOS ONE 3, e3974.

6. Jeon TI, Zhu B, Larson JL, et al. (2008) SREBP-2 regulates gut peptide secretion through intestinal bitter taste receptor signaling in mice. J Clin Invest 118, 3693-3700.
7. Janssen S, Laermans J, Verhulst PJ, et al. (2011) Bitter taste receptors and $\alpha$-gustducin regulate the secretion of ghrelin with functional effects on food intake and gastric emptying. Proc Natl Acad Sci 108, 2094-2099.

8. Mani V, Hollis J \& Gabler NK (2012) Bitter compounds decrease gastric emptying and influence intestinal nutrient transport. Animal Industry Report. AS 658, ASL R2725. http:// lib.dr.iastate.edu/ans_air/vol658/iss1/57

9. Andreozzi P, Sarnelli G, Pesce M, et al. (2015) The bitter taste receptor agonist quinine reduces calorie intake and increases the postprandial release of cholecystokinin in healthy subjects. I Neurogastroenterol Motil 21, 511-519.

10. Cristino L, Becker T \& Di Marzo V (2014) Endocannabinoids and energy homeostasis: an update. Biofactors $\mathbf{4 0}$, 389-397.

11. Tomassini Barbarossa I, Carta G, Murru E, et al. (2013) Taste sensitivity to 6- $n$-propylthiouracil is associated with endocannabinoid plasma levels in normal-weight individuals. Nutrition 29, 531-536.

12. Tepper BJ, Banni S, Melis M, et al. (2014) Genetic sensitivity to the bitter taste of 6 - $n$-propylthiouracil (PROP) and its association with physiological mechanisms controlling body mass index (BMI). Nutrients 6, 3363-3381.

13. Yajima H, Ikeshima E, Shiraki M, et al. (2004) Isohumulones, bitter acids derived from hops, activate both peroxisome proliferator-activated receptor $\alpha$ and $\gamma$ and reduce insulin resistance. J Biol Chem 279, 33456-33462.

14. Obara K, Mizutani M, Hitomi Y, et al. (2009) Isohumulones, the bitter component of beer, improve hyperglycemia and decrease body fat in Japanese subjects with prediabetes. Clin Nutr 28, 278-284.

15. Berridge KC (2009) 'Liking' and 'wanting' food rewards: brain substrates and roles in eating disorders. Physiol Behav 97, $537-550$.

16. Mueller KL, Hoon MA, Erlenbach I, et al. (2005) The receptors and coding logic for bitter taste. Nature 434, 225-229. 
17. Prescott MJ, Buchanan-Smith HM \& Smith AC (2005) Social interaction with non-averse group-mates modifies a learned food aversion in single- and mixed-species groups of tamarins (Saguinus fuscicollis and S. labiatus). Am J Primatol 65, 313-326.

18. Sørensen LB, Møller P, Flint A, et al. (2003) Effect of sensory perception of foods on appetite and food intake: a review of studies on humans. Int J Obes Relat Metab Disord 27, $1152-1166$

19. Champagne CP \& Fustier P (2007) Microencapsulation for the improved delivery of bioactive compounds into foods. Curr Opin Biotechnol 18, 184-190.

20. Aberham A, Pieri V, Croom EM Jr, et al. (2011) Analysis of iridoids, secoiridoids and xanthones in Centaurium erythraea, Frasera caroliniensis and Gentiana lutea using LC-MS and RP-HPLC. J Pharm Biomed Anal 20, 517-525.

21. Shirai Y, Sogo K, Yamamoto K, et al. (1993) A novel fine granule system for masking bitter taste. Biol Pharm Bull 16, 172-177.

22. Papillo VA, Vitaglione P, Graziani G, et al. (2014) Release of antioxidant capacity from five plant foods during a multistep enzymatic digestion protocol. I Agric Food Chem 62, 4119-4126.

23. Lam PM, Marczylo TH \& Konje JC (2010) Simultaneous measurement of three $N$-acylethanolamines in human bio-matrices using ultra performance liquid chromatography-tandem mass spectrometry. Anal Bioanal Chem 398, 2089-2097.

24. Mennella I, Savarese M, Ferracane R, et al. (2015) Oleic acid content of a meal promotes oleoylethanolamide response and reduces subsequent energy intake in humans. Food Funct $\mathbf{6}$, 204-210.

25. Vitaglione P, Lumaga RB, Montagnese C, et al. (2010) Satiating effect of a barley beta-glucan-enriched snack. J Am Coll Nutr 29, $113-121$

26. World Health Organization (2001) WHO Monographs on Selected Medicinal Plants. Geneva, Switzerland: WHO Press, World Health Organization.

27. Mennella I, Ferracane R, Zucco F, et al. (2015) Food liking enhances the plasma response of 2-arachidonoylglycerol and of pancreatic polypeptide upon modified sham feeding in humans. J Nutr 145, 2169-2175.

28. Deloose E, Corsetti M, Van Oudenhove L, et al. (2013) In man intragastric administration of the bitter compound denatonium benzoate decreases hunger and the occurrence of gastric phase III in the fasting state. AGA Abstracts Su 2070, S-548.

29. Verschueren S, Janssen P, Andrews CN, et al. (2013) The effect of the bitter taste receptor agonist denatonium benzoate on gastric emptying, satiety and return of hunger after a meal in healthy volunteers. AGA Abstracts Su 2071, S-548.

30. Collins PJ, Houghton LA, Read NW, et al. (1991) Role of the proximal and distal stomach in mixed solid and liquid meal emptying. Gut 32, 615-619.

31. McClements DJ \& Li Y (2010) Structured emulsion-based delivery systems: controlling the digestion and release of lipophilic food components. Adv Colloid Interface Sci 159, 213-228.

32. Park J, Kim KS, Kim KH, et al. (2015) GLP-1 secretion is stimulated by 1,10-phenanthroline via colocalized T2R 5 signal transduction in human enteroendocrine L cell. Biochem Biophys Res Commun 468, 306-311.

33. Kim KS, Egan JM \& Jang HJ (2014) Denatonium induces secretion of glucagon-like peptide-1 through activation of bitter taste receptor pathways. Diabetologia 102, 117-125.

34. Suh HW, Lee KB, Kim KS, et al. (2015) A bitter herbal medicine Gentiana scabra root extract stimulates glucagonlike peptide-1 secretion and regulates blood glucose in $\mathrm{db} / \mathrm{db}$ mouse. J Ethnopharmacol 172, 219-226.

35. Wölfle U, Elsholz FA, Kersten A, et al. (2015) Expression and functional activity of the bitter taste receptors TAS2R1 and TAS2R38 in human keratinocytes. Skin Pharmacol Physiol 28, 137-146.

36. Sakata I \& Sakai T (2010) Ghrelin cells in the gastrointestinal tract. Int J Peptides 2010, 1-7.

37. Halford JC \& Harrold JA (2012) Satiety-enhancing products for appetite control: science and regulation of functional foods for weight management. Proc Nutr Soc 71, 350-362.

38. Chambers L, McCrickerda K \& Yeomans MR (2015) Optimising foods for satiety. Trends Food Sci Technol 41, 149e160. 